\title{
Shea (Vitellaria paradoxa C. F. Gaertn.) seedlings showed impressive recovery after defoliation
}

\author{
F. D. Ugese ${ }^{*}$, P. T. Ezechukwu, C. Ogbaje \\ Department of Crop Production, University of Agriculture, P M B 2373, Makurdi, Nigeria \\ *E-mail address: f_ugese@yahoo.com
}

Keywords: Shea; Vitellaria paradoxa; growth; dry matter; seed size; watering interval

\begin{abstract}
Experiments to determine the effect of seed size, watering interval and defoliation on growth and dry matter attributes of seedlings of shea butter tree were conducted at Makurdi, Nigeria, from July 2010 to April, 2012. In the first experiment, treatments were made up of three seed size categories described as small (5-10g), medium (11-15g) and large (16-20g) and three watering intervals of 3, 6 and 9 days. In the second experiment, treatments comprised three watering intervals of 3, 6 and 9 days and three levels of defoliation $-0,50$ and $100 \%$. In both experiments, factorial combinations of the treatments were laid out in completely randomized design (CRD) and replicated three times. Results of analysis of variance showed that in the first experiment seed size significantly influenced root length with the medium and large seeds producing seedlings with comparatively longer roots than the small seeds. The most frequently watered seedlings ( 3 and 6 days) produced more leaves than those watered less frequently (9 days). Seed size influenced dry weight of root and total (whole plant) dry weight with the medium and large seeds recording significantly higher values than the small seeds. Watering interval however did not significantly influence any of the other traits. Seed weight exerted significant influence on amount of dry matter partitioned to the stem and the root. More dry matter was partitioned to the stem by the small seeds. Conversely, medium and large seeds allocated more dry matter to the root than to the stem. In the second experiment, defoliation level only influenced total fresh weight, dry weight of root and total dry weight in favour of plants with half their leaves removed. None of the traits examined were significantly influenced by watering regime. Interaction between defoliation level and watering regime significantly influenced total fresh weight, dry weight of root and total dry weight. Generally seed size had more influence on seedling characters than watering interval. Seedlings also demonstrated remarkable ability to overcome effects of defoliation.
\end{abstract}

\section{INTRODUCTION}

The savanna is an expansive bioclimatic zone in Africa. Although its precise boundaries may not be readily established, it is estimated to cover close to $60 \%$ of tropical Africa (Okigbo, 1985). The tropical savanna zone is defined by dry periods lasting between 2.5 and 7.5 months (Harris, 1980) or up to 10 months if the semi-arid areas are considered (Phillips, 1959). The African savanna, as that of other parts of the world, is characterized by a mixture of grasses and trees of varying density across its range. The zone expands across most of the countries of tropical Africa covering about 45 countries (Ker, 1995).

One of the features of interest of the African savanna environment is its inherent low capacity for sustainable productivity. For instance, it is evident that most savanna soils are sandy with shallow depths and therefore highly erodible (Kowal and Kassam, 1978). This disadvantage could be further worsened by overgrazing (Douglass et. al., 2011) and the annual bush fires that leave the soil surface without vegetative cover. Besides this, temperatures are generally high (Ker, 1995) with attendant severe impacts on evapotranspiration rates. Prevailing challenges posed by climate change have important implications on tree survival and growth.

Vitellaria paradoxa is one of the prominent tree species inhabiting the African savanna. In Nigeria its zone of major occurrence extends from the southern guinea savanna to the sudan 
savanna (Keay, 1989). Its occurrence along water courses has been reported in sahelian areas (ICRAF, 2000). As noted earlier, the savanna zone is characterized by certain environmental disturbances such as moisture stress, high temperatures, overgrazing and annual bush fires. Even though the species is reported to adapt to these conditions, it could nevertheless, succumb to them (ICRAF, 2000). That Vitellaria is able to thrive under these conditions could testify to certain adaptive features. This must have prompted its recommendation as a species to fight desertification in northern Ghana (Dogbevi, 2007). This is in addition to the nutritional and socio-economic usefulness of the tree. In the face of climate change with associated elevated temperatures and moisture stress, trees with greater resilience could assume greater importance. It has therefore become pertinent to examine more closely the behaviour of this species under these unfavourable conditions. We therefore embarked on this study to investigate the effects of seed size, watering interval and defoliation on seedling growth and dry matter attributes of Vitellaria paradoxa. Findings could form a sound basis for species recommendation for climate change mitigation.

\section{MATERIALS AND METHODS}

\section{- Experiment 1}

Seeds of the shea butter tree were obtained from fallen fruits of the species around the premises of the University of Agriculture Makurdi in early July 2010. The seeds were weighed individually and separated into the following three categories: 5-10g, 11-15g and 16-20g designated as small, medium and large respectively. Sowing of seeds was done on $7^{\text {th }}$ July 2010 in perforated 7-litre plastic containers filled with topsoil in the nursery of the Teaching and Research Farm of the University of Agriculture Makurdi $\left(7.41^{\circ} \mathrm{N}, 8.37^{\circ} \mathrm{E}, 97 \mathrm{~m}\right.$ above mean sea level). Topsoil used was a sandy loam with $\mathrm{pH}\left(\mathrm{H}_{2} \mathrm{O}\right)$, organic matter, Nitrogen and Phosphorus (Bray-1) contents of 6.25, $1.59 \%, 0.101 \%$ and $3.75 \mathrm{ppm}$ respectively. $\mathrm{Ca}, \mathrm{Mg}, \mathrm{Na}$ and $\mathrm{K}$ concentrations (centimol $/ \mathrm{kg}$ soil) were $3.60,1.98,0.75$ and 1.16 , in that order. CEC was 7.99 centimol $/ \mathrm{kg}$ soil.

Treatments consisted of the three seed sizes specified above and three watering intervals of 3 , 6 and 9 days. Factorial combinations of seed size and watering interval were laid out in completely randomized design (CRD) and replicated three times. The watering schedule was commenced 26 weeks after planting (WAP) and continued for 14 weeks. Watering was done liberally to allow free drainage of water through the perforations.

At the end of the 14 weeks, data were taken on certain aspects of seedling growth namely, plant height, seedling girth, number of leaves, leaf length and leaf width. Leaf area was derived from the last two traits using the relationship LA $=4.41+1.14 \mathrm{LW}$ (Ugese et al., 2008a), where LA is adaxial leaf area $\left(\mathrm{cm}^{2}\right)$ and LW is the product of leaf length $(\mathrm{cm})$ and leaf width $(\mathrm{cm})$.

The seedlings were carefully removed from the containers, roots washed in clean water and seedlings segmented into roots, stems and leaves. Length of the longest root was also measured. The different seedling parts were weighed fresh and also after oven drying to a constant weight at $70^{\circ} \mathrm{C}$. Dry matter content was calculated as the fresh weight over the dry weight of the seedling part concerned (leaf, shoot or root) multiplied by 100. Similarly, dry matter partitioning was estimated as the ratio of dry weight of the particular seedling portion (leaf, shoot or root) to whole seedling dry weight expressed as a percentage.

\section{- Experiment 2.}

Seeds of the shea tree were obtained from ripe fallen fruits of naturally occurring stands at the University of Agriculture Makurdi on July 7, 2011. The seeds were planted as in Experiment 1 on soil of similar physico-chemical characteristics to that of the first experiment. Planting date was July 9, 2011.The experiment was a factorial consisting of 3 defoliation levels $(0,50$ and 100\%) and 3 watering intervals (3, 6 and 9 days) arranged in a completely randomized design and replicated 3 times. Defoliation of 4 tagged plants from each treatment combination in each of the 3 replications was done 26WAP after which the watering schedule was imposed for 12 weeks. Watering was done to field capacity to enable free flow of water through the perforations at the bottom of the plastic containers. 
Seedling growth attributes were taken 6 and 12 weeks respectively from time of defoliation. After seedling harvest at terminal point of the experiment (12 weeks from defoliation), seedlings were demarcated into leaves, shoots and roots and their fresh and oven dry weights measured. Dry matter content and dry matter partitioning were obtained as in Experiment 1.

\section{STATISTICAL ANALYSES}

Analysis of variance (ANOVA) was performed on the data collected using GENSTAT discovery edition 3 release 7.2 DE (GENSTAT, 2007). Where significant F-test occurred, means were separated using Fisher's least significant difference (F-LSD) at 5\% level of significance.

\section{RESULTS}

\section{- Experiment 1}

Results of statistical analysis generally showed low level of significant differences. No significant response was observed as a result of interaction between seed size and watering schedule.

A summary of the main effect of the factors on seedling growth is presented in Table 1. None of the growth attributes responded significantly to weight of seed except length of longest root with the larger seed categories having significantly longer roots compared to the small seeds. Similarly only number of leaves showed significant response to watering schedule with the 3 and 6 day watering intervals producing higher number of leaves. Even though watering interval had no significant influence on length of longest root, seedlings that were less frequently watered (6 and 9 days) showed a strong tendency to grow longer roots.

Fresh and dry weight properties of shea seedlings also showed minimal response to treatments (Table 2). Thus seed size influenced dry weight of root and total (whole plant) dry weight. In both traits, medium and large seeds had significantly higher values than the small seeds. The latter also tended towards lower values in most of the other traits. Watering interval on the other hand did not significantly influence any of the traits.

A summary of the dry matter content and partitioning as influenced by the factors is presented in Table 3. Seed weight exerted significant influence on amount of dry matter partitioned to the stem and the root. More dry matter was partitioned to the shoot by the small seeds. Conversely, medium and large seeds allocated more dry matter to the root than to the shoot. The small seeds also tended to allocate more dry matter to the leaves compared to the other seed categories. Watering schedule did not affect any of the dry matter traits to any marked degree.

\section{- Experiment 2}

Effect of degree of leaf removal and watering regime on growth parameters of Vitellaria seedlings at 26 and 38 WAP (Table 4) did not show statistical significance. However, in most characters considered, control plants tended to have lower values. Similarly, seedling characters evaluated did not show any remarkable response to watering interval. A summary of treatment effect on fresh and dry weight attributes as presented in Table 5 indicates that defoliation level had a marked effect on total fresh weight, dry weight of root and whole plant dry weight. Seedlings with half of their foliage removed recorded higher values in the above attributes while intact (control) seedlings had the least values. Watering frequency recorded a non-significant effect on seedling fresh and dry weights.

Influence of defoliation level and watering regime was not noticeable on dry matter content and partitioning pattern (Table 6). Dry matter allocated to the root tended in favour of seedlings watered every 9 days. In general, dry matter allocation pattern to the component parts of the seedling in the order of magnitude was root $>$ shoot $>$ leaves.

Interaction effect of defoliation and watering regime elicited some significant responses in some fresh and dry weights attributes of shea seedlings (Table 7). Specifically, seedlings receiving $0 \%$ defoliation recorded the highest fresh root weight when watered every 3 days while those whose foliage were $50 \%$ defoliated recorded statistically similar performance across watering intervals. 
Completely defoliated seedlings performed better when subjected to watering every 6 and 9 days. Dry weight of root of intact seedlings was better with the 3 days watering schedule while that of partially defoliated seedlings was better with the 3 and 6 days schedules. Seedlings with entire leaves removed tended to show better results with the 6 and 9 days watering. Results of total dry weight followed similar pattern except that non defoliated seedlings were better off at the 3 and 9 day watering frequency.

\section{DISCUSSION}

Although larger seed size categories did not differ statistically from the smaller ones in many of the traits examined, they showed superiority in such key traits as root length, root dry weight, whole plant dry weight and amount of dry matter allocated to the root. The performance of larger seeds over and above smaller ones has been clearly observed in Vitellaria paradoxa (Ugese et al. 2007; 2008b) as well as in other species (Negi and Todaria, 1997; Khurana and Singh, 2000). This is usually attributed to higher levels of stored food in the weightier seeds. This observation holds true when considering both between and within species growth attributes. Species with heavier seeds normally produce seedlings with faster growth rate (Seiwa and Kikuzawa, 1991), and within a species, larger seed classes have been known to perform better than the smaller ones (Negi and Todaria, 1997). In the shea species, different provenances from Nigeria showed remarkable variation in growth to the detriment of provenances with smaller seeds (Ugese et al. 2011a).

Although large seeds were able to outclass the smaller ones in some particular traits, their superior performance was not as overwhelming as the more or less consensus opinion seems to suggest. Reports from several species are unequivocal that seedlings derived from larger seeds manifest faster growth compared to those derived from smaller seeds (Gupta et al., 1983; Negi and Todaria, 1997). In addition, it has been specifically noted that heavier seeds produce seedlings that show better performance under sub-optimal growth circumstances (Coomes and Grubb, 2003), exhibiting greater tolerance to water stress conditions (Leishman and Westoby, 1994). Results we obtained did not give larger seeds clear advantage in this regard. Interestingly, Sánchez-Gómez et al. (2006) obtained results in which seedlings from large seeds experienced the most mortality under drought conditions. Such seeming deviations could give credence to the suggestion by Sack et al. (2003) that drought tolerance could be linked to several traits and not just seed size. This opinion has been supported by Sánchez-Gómez et al. (2006)

The longer roots developed by the larger seed categories could result from their having greater food reserves, as noted above. In Vitellaria, much emphasis is given to root development probably as an adaptation for survival in the savanna environment (Ugese et al. 2010). In the present study, longest root length of seedlings did not show significant response to watering regime although it was evident that seedlings subjected to the longest watering interval (9 days), tended to have comparatively longer roots. In a previous study, the ability of the 9 day watering schedule to produce seedlings with longer roots was significant and was attributed to the tendency of roots to scavenge for water in a moisture stressed environment (Ugese et al., 2008b). This is in conformity with reports in two urban tree species (Zainudin et al., 2003). The positive response of number of leaves to watering frequency contrasts with results of a previous work (Ugese et al., 2008b). However the higher number of leaves in more frequently watered plants could not translate to higher leaf area. Fresh and dry weights of seedlings were only marginally influenced by seed size in favour of the larger seed categories and could result from higher amounts of stored food as mentioned earlier.

In the present study, effect of watering on root length was not clear cut; an earlier investigation (Ugese et al., 2008b) had shown that water stressed plants respond by producing longer roots. Similar response has been reported in other species including Hopea odorata and Mimusops elengi (Zainudin et al., 2003). It could well be considered a conclusive matter that under water stressed conditions, plants change their pattern of assimilate partitioning in favour of the root, judging from the higher root: shoot ratios (Khurana and Singh, 2000; Zainudin et al., 2003). In our study, root: shoot ratio was not estimated but dry matter partitioned to the root varied non- 
significantly when averaged over watering regimes. However, in the second experiment, the tendency of the root to accumulate more dry matter was more clearly pronounced.

It was curious that seedlings from small seeds allocated more dry matter to the shoot while those from large seeds allocated more dry matter to the root than to the shoot. This disparity in dry matter allocation pattern may be linked with amount of food reserves in the different seed categories and adaptive behaviour of the species in its habitat. It is probable that smaller seeds, with more restricted food reserves, were able to exhaust such more quickly than larger seeds. As such, they had to divert more photosynthate to the above ground portion which is responsible for photosynthesis as a way of supporting the growing seedling. The larger seeds, with greater reserves, concentrated on root development since stored food was not quickly exhausted. This is likely the case since in Vitellaria, considerable attention is given to root development, a critical factor for survival in the harsh savanna climate (Ugese et al., 2010). It is possible that, seedlings resulting from large seeds may show better survival in the face of repeated or prolonged environmental challenges peculiar to their existence. This would however need more empirical studies for more definitive conclusions.

Defoliation level was observed to show significant effect only on few seedling fresh/dry weight attributes. That control seedlings showed comparatively lower values of total fresh weight, dry weight of root and whole plant dry weight is suggestive of the superior recovery properties of this species. This behaviour is comparable to that obtained in Casearia nitida, a tropical tree species in which foliage replacement was greater in defoliated than non-defoliated plants (Boege, 2005). However, in a previous study (Ugese et al. 2011b), no noticeable differences in growth were observed between defoliated and intact seedlings.

It is noteworthy that no difference in growth pattern of seedlings in response to defoliation and watering treatment was observed when this was assessed early (26 WAP) and late (38 WAP). Ugese et al. (2011b) had reported observations of a non-significant effect of treatment on seedling growth at the terminal point of the experiment and inferred that such differences must have occurred early in the life of the seedling, cancelling out later. However, with the present result it has become more evident that Vitellaria species may have an in-built mechanism to neutralize to a large extent effect of disturbances to its growth even at a relatively early stage.

Intact seedlings when watered every 3 days in contrast to those subjected to complete leaf removal produced higher number of leaves. This could be expected considering that non-defoliated seedlings would present greater transpiration surface and thereby need more water to replace the amount lost to the atmosphere. Those seedlings whose leaves were removed would need less water since moisture loss from leaf surfaces may not constitute a serious threat to normal physiological functions. In fact, it could be that too much water from frequent watering may constitute an abnormal environment to tree performance under such circumstances. Shea seedling behaviour in this case would serve to explain why savanna plants generally shed their leaves during environmental stress conditions such as moisture deficiency.

As stated earlier, this behaviour explains one of the key strategies of tree survival in the savanna environment characterized by bush fires, drought (Ugese et al., 2011a) and inappropriate animal grazing regimes (Douglass et al., 2011). Thus in most cases, biotic and abiotic stresses leave the plant with no foliage or at most very scanty foliage. Under such conditions, more frequent watering may even produce seedlings with inferior growth. This is informative in that in managed plantations, intact seedlings may be expected to receive more frequent watering than those with zero or incomplete foliage.

Results of this study point to the better seedling performance of larger seed categories and the great capacity of shea seedlings to recover from defoliation. This capacity makes the shea tree an outstanding species for the savanna in the face of climate change characterised by a worsening soil moisture status. 


\section{CONCLUSIONS}

Experiments to determine the effect of seed size, watering interval and defoliation on growth and dry matter attributes of seedlings of shea butter tree were conducted at Makurdi, Nigeria, from July 2010 to April, 2012.

Results of analysis of variance showed that in the first experiment seed size significantly influenced root length with the medium and large seeds producing seedlings with comparatively longer roots than the small seeds. The most frequently watered seedlings ( 3 and 6 days) produced more leaves than those watered less frequently ( 9 days). Seed size influenced dry weight of root and total (whole plant) dry weight with the medium and large seeds recording significantly higher values than the small seeds. Watering interval however did not significantly influence any of the other traits. Seed weight exerted significant influence on amount of dry matter partitioned to the stem and the root. More dry matter was partitioned to the stem by the small seeds. Conversely, medium and large seeds allocated more dry matter to the root than to the stem. In the second experiment, defoliation level only influenced total fresh weight, dry weight of root and total dry weight in favour of plants with half their leaves removed. None of the traits examined were significantly influenced by watering regime. Interaction between defoliation level and watering regime significantly influenced total fresh weight, dry weight of root and total dry weight. Generally seed size had more influence on seedling characters than watering interval. Seedlings also demonstrated remarkable ability to overcome effects of defoliation.

Table 1. Effect of seed size and watering interval on growth of shea seedlings at Makurdi, Nigeria.

\begin{tabular}{|c|c|c|c|c|c|c|c|}
\hline Treatment & $\begin{array}{l}\text { Plant } \\
\text { height } \\
(\mathrm{cm})\end{array}$ & $\begin{array}{l}\text { Number } \\
\text { of leaves }\end{array}$ & $\begin{array}{l}\text { Leaf } \\
\text { length } \\
(\mathrm{cm})\end{array}$ & $\begin{array}{l}\text { Leaf } \\
\text { width } \\
(\mathrm{cm})\end{array}$ & $\begin{array}{l}\text { Leaf area } \\
\left(\mathrm{cm}^{2}\right)\end{array}$ & $\begin{array}{l}\text { Stem girth } \\
(\mathrm{cm})\end{array}$ & $\begin{array}{l}\text { Root length } \\
(\mathrm{cm})\end{array}$ \\
\hline \multicolumn{8}{|l|}{ Seed Size } \\
\hline Small & 2.45 & 3.34 & 7.09 & 3.03 & 30.0 & 0.251 & 47.1 \\
\hline Medium & 3.16 & 3.33 & 8.73 & 3.74 & 42.3 & 0.303 & 76.6 \\
\hline Large & 2.96 & 3.18 & 8.23 & 3.26 & 35.4 & 0.283 & 54.7 \\
\hline $\operatorname{LSD}_{(0.05)}$ & NS & NS & NS & NS & NS & NS & 19.45 \\
\hline \multicolumn{8}{|c|}{ Watering Interval (Days) } \\
\hline 3 & 2.80 & 3.41 & 7.71 & 3.34 & 34.8 & 0.290 & 49.8 \\
\hline 6 & 3.17 & 3.79 & 8.19 & 3.23 & 35.1 & 0.280 & 65.5 \\
\hline 9 & 2.60 & 2.65 & 8.15 & 3.46 & 37.8 & 0.268 & 63.1 \\
\hline $\operatorname{LSD}_{(0.05)}$ & NS & 0.682 & NS & NS & NS & NS & NS \\
\hline
\end{tabular}

Table 2. Effect of seed size and watering interval on fresh and dry weight of shea seedlings at Makurdi, Nigeria.

\begin{tabular}{lllllllll}
\hline Treatment & $\begin{array}{l}\text { Fresh wt } \\
\text { of leaf } \\
(\mathrm{g})\end{array}$ & $\begin{array}{l}\text { Fresh wt } \\
\text { of stem } \\
(\mathrm{g})\end{array}$ & $\begin{array}{l}\text { Fresh wt } \\
\text { of root } \\
(\mathrm{g})\end{array}$ & $\begin{array}{l}\text { Total } \\
\text { fresh wt } \\
(\mathrm{g})\end{array}$ & $\begin{array}{l}\text { Dry wt } \\
\text { of leaf } \\
(\mathrm{g})\end{array}$ & $\begin{array}{l}\text { Dry wt } \\
\text { of stem } \\
(\mathrm{g})\end{array}$ & $\begin{array}{l}\text { Dry wt } \\
\text { of root } \\
(\mathrm{g})\end{array}$ & $\begin{array}{l}\text { Total } \\
\text { dry wt } \\
(\mathrm{g})\end{array}$ \\
\hline $\begin{array}{l}\text { Seed Size } \\
\text { Small }\end{array}$ & 0.37 & 0.50 & 6.18 & 7.05 & 0.17 & 0.32 & 2.19 & 2.68 \\
Medium & 0.51 & 0.76 & 8.92 & 10.18 & 0.22 & 0.34 & 3.61 & 4.18 \\
Large & 0.53 & 0.74 & 8.16 & 9.43 & 0.20 & 0.29 & 3.43 & 3.92 \\
LSD $(0.05)$ & $N S$ & $N S$ & NS & NS & NS & NS & 0.833 & 0.428 \\
Watering Interval (Days) & & & & & & \\
3 & 0.45 & 0.70 & 7.44 & 8.60 & 0.19 & 0.32 & 3.10 & 3.16 \\
6 & 0.50 & 0.74 & 7.84 & 9.08 & 0.20 & 0.33 & 2.89 & 3.42 \\
9 & 0.45 & 0.55 & 7.98 & 8.99 & 0.19 & 0.30 & 3.25 & 3.74 \\
LSD $_{(0.05)}$ & $\mathrm{NS}$ & $\mathrm{NS}$ & $\mathrm{NS}$ & $\mathrm{NS}$ & $\mathrm{NS}$ & $\mathrm{NS}$ & $\mathrm{NS}$ & $\mathrm{NS}$ \\
\hline
\end{tabular}


Table 3. Effect of seed size and watering interval on dry matter content (\%) and partitioning (\%) of shea seedlings at Makurdi, Nigeria.

\begin{tabular}{|c|c|c|c|c|c|c|c|}
\hline Treatment & $\begin{array}{l}\text { Dry } \\
\text { matter } \\
\text { content of } \\
\text { leaf }\end{array}$ & $\begin{array}{l}\text { Dry } \\
\text { matter } \\
\text { content } \\
\text { of stem }\end{array}$ & $\begin{array}{l}\text { Dry } \\
\text { matter } \\
\text { content } \\
\text { of root }\end{array}$ & $\begin{array}{l}\text { Total } \\
\text { dry } \\
\text { matter } \\
\text { content }\end{array}$ & $\begin{array}{l}\text { Dry } \\
\text { matter } \\
\text { partitioned } \\
\text { to leaf }\end{array}$ & $\begin{array}{l}\text { Dry matter } \\
\text { partitioned } \\
\text { to stem }\end{array}$ & $\begin{array}{l}\text { Dry matter } \\
\text { partitioned } \\
\text { to root }\end{array}$ \\
\hline \multicolumn{8}{|l|}{ Seed Size } \\
\hline Small & 48.5 & 54.7 & 36.2 & 38.8 & 6.46 & 12.94 & 80.06 \\
\hline Medium & 45.5 & 42.4 & 41.2 & 41.8 & 5.47 & 8.26 & 86.3 \\
\hline Large & 40.4 & 42.0 & 42.7 & 42.2 & 5.48 & 7.43 & 87.6 \\
\hline $\operatorname{LSD}_{(0.05)}$ & NS & NS & NS & NS & NS & 3.927 & 5.34 \\
\hline \multicolumn{8}{|c|}{ Watering Interval (Days) } \\
\hline 3 & 46.8 & 43.7 & 41.2 & 41.9 & 5.48 & 9.80 & 84.7 \\
\hline 6 & 44.8 & 44.0 & 38.0 & 39.2 & 6.17 & 9.89 & 83.9 \\
\hline 9 & 42.7 & 51.5 & 40.8 & 41.7 & 5.29 & 8.74 & 85.8 \\
\hline $\operatorname{LSD}_{(0.05)}$ & NS & NS & NS & NS & NS & NS & NS \\
\hline
\end{tabular}

Table 4. Effect of defoliation level and watering interval on seedling growth attributes of shea (Vitellaria paradoxa) seedlings at Makurdi, Nigeria

\begin{tabular}{|c|c|c|c|c|c|c|c|c|c|c|c|c|c|}
\hline 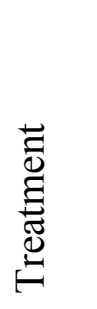 & 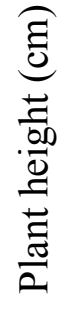 & 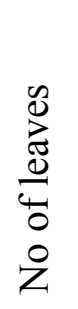 & 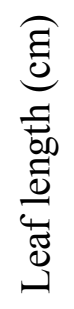 & 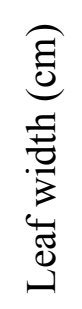 & 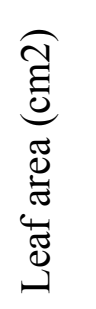 & 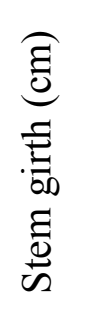 & 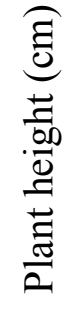 & 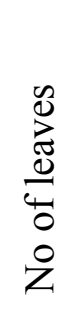 & 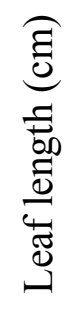 & 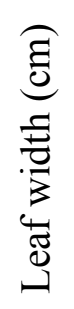 & 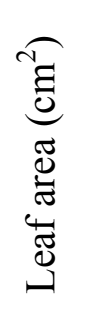 & 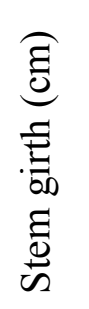 & 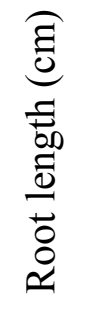 \\
\hline \multicolumn{14}{|c|}{ Defoliation level (\%) } \\
\hline 0 & 3.2 & 3.0 & 5.0 & 2.2 & 17.5 & 0.22 & 4.1 & 3.4 & 5.6 & 2.3 & 20.3 & 0.22 & 69.8 \\
\hline 50 & 3.4 & 2.7 & 6.2 & 2.6 & 24.0 & 0.22 & 4.0 & 2.9 & 7.2 & 3.0 & 29.9 & 0.22 & 85.6 \\
\hline 100 & 3.5 & 3.0 & 6.3 & 2.6 & 24.1 & 0.21 & 4.2 & 3.5 & 6.4 & 2.6 & 24.2 & 0.21 & 64.9 \\
\hline LSD & NS & NS & NS & NS & NS & NS & NS & NS & NS & NS & NS & NS & NS \\
\hline \multicolumn{14}{|c|}{ Watering interval (Days) } \\
\hline 3 & 3.8 & 2.8 & 6.0 & 2.6 & 22.5 & 0.22 & 4.5 & 3.4 & 7.1 & 3.0 & 29.3 & 0.22 & 72.2 \\
\hline 6 & 3.2 & 3.2 & 5.4 & 2.2 & 19.1 & 0.21 & 4.1 & 3.5 & 6.0 & 2.4 & 21.3 & 0.22 & 61.2 \\
\hline 9 & 3.0 & 2.5 & 6.2 & 2.6 & 24.1 & 0.21 & 3.7 & 2.8 & 6.2 & 2.5 & 23.9 & 0.21 & 79.8 \\
\hline LSD & NS & NS & NS & NS & NS & NS & NS & NS & NS & NS & NS & NS & NS \\
\hline
\end{tabular}


Table 5. Main effect of defoliation and watering interval on fresh and dry weight attributes of Vitellaria seedlings $38 \mathrm{WAP}$ at Makurdi, Nigeria

\begin{tabular}{|c|c|c|c|c|c|c|c|c|}
\hline Treatment & $\begin{array}{l}\text { Fresh wt } \\
\text { of } \\
\text { leaves } \\
(\mathrm{g})\end{array}$ & $\begin{array}{l}\text { Fresh wt } \\
\text { of shoot } \\
\text { (g) }\end{array}$ & $\begin{array}{l}\text { Fresh wt } \\
\text { of root } \\
(\mathrm{g})\end{array}$ & $\begin{array}{l}\text { Total } \\
\text { fresh wt } \\
\text { (g) }\end{array}$ & $\begin{array}{l}\text { Dry wt } \\
\text { of } \\
\text { leaves } \\
(\mathrm{g})\end{array}$ & $\begin{array}{l}\text { Dry wt } \\
\text { of shoot } \\
\text { (g) }\end{array}$ & $\begin{array}{l}\text { Dry wt } \\
\text { of root } \\
\text { (g) }\end{array}$ & $\begin{array}{l}\text { Total } \\
\text { dry wt } \\
\text { (g) }\end{array}$ \\
\hline \multicolumn{9}{|c|}{ Defoliation level (\%) } \\
\hline 0 & 0.27 & 0.83 & 6.8 & 7.8 & 0.12 & 0.32 & 3.1 & 3.5 \\
\hline 50 & 0.45 & 1.02 & 8.1 & 9.6 & 0.20 & 0.42 & 3.6 & 4.3 \\
\hline 100 & 0.36 & 0.89 & 7.0 & 8.0 & 0.17 & 0.35 & 3.2 & 3.7 \\
\hline $\operatorname{LSD}_{(0.05)}$ & NS & NS & NS & 1.25 & NS & NS & 0.48 & 0.58 \\
\hline \multicolumn{9}{|c|}{ Watering interval (Days) } \\
\hline 3 & 0.39 & 0.87 & 7.1 & 8.4 & 0.18 & 0.38 & 3.4 & 4.0 \\
\hline 6 & 0.33 & 0.98 & 7.3 & 8.4 & 0.15 & 0.39 & 3.2 & 3.8 \\
\hline 9 & 0.35 & 0.88 & 7.4 & 8.6 & 0.15 & 0.32 & 3.2 & 3.7 \\
\hline $\operatorname{LSD}_{(0.05)}$ & NS & NS & NS & NS & NS & NS & NS & NS \\
\hline
\end{tabular}

Table 6. Main effect of defoliation and watering interval on dry matter content (\%) and partitioning $(\%)$ of Vitellaria seedlings 38 WAP at Makurdi, Nigeria.

\begin{tabular}{|c|c|c|c|c|c|c|c|}
\hline Treatment & $\begin{array}{l}\text { Dry } \\
\text { matter } \\
\text { content } \\
\text { of leaves }\end{array}$ & $\begin{array}{l}\text { Dry } \\
\text { matter } \\
\text { content of } \\
\text { shoot }\end{array}$ & $\begin{array}{l}\text { Dry } \\
\text { matter } \\
\text { content } \\
\text { of roots }\end{array}$ & $\begin{array}{l}\text { Total dry } \\
\text { matter } \\
\text { content }\end{array}$ & $\begin{array}{l}\text { Dry } \\
\text { matter } \\
\text { partitioned } \\
\text { to leaves }\end{array}$ & $\begin{array}{l}\text { Dry } \\
\text { matter } \\
\text { partitioned } \\
\text { to shoot }\end{array}$ & $\begin{array}{l}\text { Dry } \\
\text { matter } \\
\text { partitioned } \\
\text { to roots }\end{array}$ \\
\hline \multicolumn{8}{|c|}{ Defoliation level (\%) } \\
\hline 0 & 50.1 & 40.1 & 45.4 & 44.8 & 3.4 & 9.5 & 87.2 \\
\hline 50 & 44.6 & 40.9 & 45.2 & 44.6 & 4.6 & 9.6 & 85.8 \\
\hline 100 & 48.0 & 39.4 & 46.3 & 46.6 & 4.5 & 9.2 & 86.2 \\
\hline $\operatorname{LSD}_{(0.05)}$ & NS & NS & NS & NS & NS & NS & NS \\
\hline \multicolumn{8}{|c|}{ Watering interval (Days) } \\
\hline 3 & 48.3 & 45.0 & 48.4 & 48.0 & 4.5 & 9.6 & 85.8 \\
\hline 6 & 45.6 & 39.7 & 44.3 & 44.3 & 3.9 & 10.6 & 85.6 \\
\hline 9 & 48.8 & 35.8 & 44.2 & 43.7 & 4.0 & 8.1 & 87.8 \\
\hline $\operatorname{LSD}_{(0.05)}$ & NS & NS & NS & NS & NS & NS & NS \\
\hline
\end{tabular}

TABLE 7: Interaction effect of defoliation and watering regime on fresh and dry weight of Vitellaria seedlings.

\begin{tabular}{|c|c|c|c|c|c|c|c|c|c|}
\hline $\begin{array}{l}\text { Defoliation } \\
\text { level (\%) }\end{array}$ & $\begin{array}{l}\text { Watering } \\
\text { frequency } \\
\text { (days) }\end{array}$ & $\begin{array}{l}\text { Fresh } \\
\text { weight } \\
\text { of leave } \\
\text { (g) }\end{array}$ & $\begin{array}{l}\text { Fresh } \\
\text { weight } \\
\text { of stem } \\
(\mathrm{g})\end{array}$ & $\begin{array}{l}\text { Fresh } \\
\text { weight } \\
\text { of root } \\
\text { (g) }\end{array}$ & $\begin{array}{l}\text { Total } \\
\text { fresh } \\
\text { weight } \\
(\mathrm{g})\end{array}$ & $\begin{array}{l}\text { Dry } \\
\text { weight } \\
\text { of leave } \\
(\mathrm{g})\end{array}$ & $\begin{array}{l}\text { Dry } \\
\text { weight } \\
\text { of stem } \\
\text { (g) }\end{array}$ & $\begin{array}{l}\text { Dry } \\
\text { weight } \\
\text { of root } \\
\text { (g) }\end{array}$ & $\begin{array}{l}\text { Total } \\
\text { dry } \\
\text { weight } \\
\text { (g) }\end{array}$ \\
\hline \multirow[t]{3}{*}{0} & 3 & 0.37 & 0.86 & 7.8 & 9.1 & 0.16 & 0.34 & 3.7 & 4.2 \\
\hline & 6 & 0.31 & 0.88 & 5.5 & 6.7 & 0.11 & 0.33 & 2.4 & 2.8 \\
\hline & 9 & 0.12 & 0.74 & 6.9 & 7.8 & 0.08 & 0.29 & 3.1 & 3.5 \\
\hline \multirow[t]{3}{*}{50} & 3 & 0.49 & 1.05 & 7.9 & 9.5 & 0.22 & 0.44 & 3.8 & 4.4 \\
\hline & 6 & 0.37 & 1.12 & 8.8 & 10.3 & 0.18 & 0.47 & 4.0 & 4.6 \\
\hline & 9 & 0.47 & 0.88 & 7.6 & 8.9 & 0.19 & 0.33 & 3.2 & 3.7 \\
\hline \multirow[t]{3}{*}{100} & 3 & 0.31 & 0.70 & 5.7 & 6.7 & 0.16 & 0.35 & 2.8 & 3.3 \\
\hline & 6 & 0.31 & 0.94 & 7.5 & 8.4 & 0.16 & 0.37 & 3.4 & 3.9 \\
\hline & 9 & 0.46 & 1.02 & 7.8 & 9.0 & 0.18 & 0.33 & 3.5 & 4.0 \\
\hline $\operatorname{LSD}_{(0.05)}$ & & $\mathrm{NS}$ & NS & 2.00 & 2.16 & NS & NS & 0.83 & 1.00 \\
\hline
\end{tabular}

$\mathrm{NS}=$ No significant difference 


\section{References}

[1] Coomes, D. A. and Grubb, P. J. 2003. Colonization, tolerance, competition and seed size variation within functional groups. Trends in Ecology and Evolution 18: 283-291

[2] Dogbevi , E. K. 2007. Ghana and the shea tree. Website:

[3] http://www.myjoyonline.com/features/200712/10987.asp. Accessed 13/2/2010

[4] Douglass, L. L., Possingham, H. P., Carwadine, J., Klein, C. J., Roxburgh, S. H.., RusselSmith, J. and Wilson, K. A. 2011. The effects of carbon credit on savanna land management and priorities for biodiversity conservation. PLoS ONE 6(9): e23843. Doi10,1371/journal.pone.0023843

[5] GENSTAT, 2007. GENSTAT Discovery Edition 3, Release 7.2DE. Lawes Agricultural Trust, Rothamstead Experimental Station, UK.

[6] Gupta, S. K., Pathak, P. S. and Roy, R. D. 1983. Seedling growth of Leucaena leucocephala(Lam.) de Wit. II. Effect of seed size. Indian Journal of Forestry 6: 202-204.

[7] Harris, D. R. 1980. Human Ecology in Savanna Environments. Academic Press, London,

[8] ICRAF. 2000. International Centre for Research in Agroforestry. Agroforestree Database2000

[9] Ker, A. 1999. Farming Systems of the African Savanna: A Continent in Crisis. IDRC, 176pp

[10] Khurana, E. and Singh, J. S. 2000. Influence of seed size on seedling growth of Albizia procera under different soil water levels. Annals of Botany 86: 1185-1192.

[11] Leishman, M. R. and Westoby, M. 1994. The role of seed size in seedling establishment in dry soil conditions - experimental evidence from semiarid species. Journal of Ecology 82: 249-258

[12] Okigbo, B. N. 1985. Land use and production potentials of African savanna. In

[13] Tothill, J. C., Mott, J. J. (Ed) Ecology and Management of the World's Savannas. Australian Academy of Science, Canberra, Australia

[14] Phillips, J. 1959. Agriculture and Ecology in Africa: A Study of Actual and Potential

[15] development South of the Sahara. Faber and Faber, London, UK. 424pp.

[16] Sack, L., Grubb, P. J. and Marańńn, T. 2003. The functional morphology of juvenile plants tolerant of strong summer drought in shaded forest understories in southern Spain. Plant Ecology 168: 139-163.

[17] Sánchez-Gómez, D., Valladares, S. and Zavala, M. S. 2006. Performance of seedlings of Mediterranean woody species under experimental gradients of irradiance and water

[18] availability: trade-offs and evidence for niche differentiation. New Phtologist 170:795-806.

[19] Seiwa, K. and Kikuzawa, K. 1991. Phenology of tree seedlings in relation to seed size. Canadian Journal of Botany 69: 532-538

[20] Ugese, F. D., Ahen, A. and Ishar, S. I. 2011b. Single defoliation had little influence on growth and dry matter attributes of shea (Vitellaria paradoxa Gaertn F.) seedlings. Forests, Trees and Livelihoods 20: 283-294.

[21] Ugese, F. D., Baiyeri, K. P. and Mbah, B. N. 2008a. Leaf area determination of shea butter tree (Vitellaria Paradoxa C. F. Gaertn.). Int. Agrophysics, 22: 167-170.

[22] Ugese, F. D., Baiyeri, K. P. and Mbah, B. N. 2008b. Effect of seed origin and watering regime on seedling growth and dry matter yield of shea butter tree (Vitellaria paradoxa Gaertn F.) seedlings. Bioresearch 6: $303-307$. 
[23] Ugese, F. D., Baiyeri, K. P. and Mbah, B. N. 2010. Determination of growth stages and seedling structures associated with slow emergence of shea butter tree (Vitellaria paradoxa C. F.Gaertn.) seedlings. Journal of Animal and Plant Sciences 8: 993-998

[24] Ugese, F. D., Baiyeri, K. P. and Mbah, B. N.2011a. Variability in seedling growth of seeds of shea butter tree (Vitellaria paradoxa C. F. Gaertn.) sourced from nine locations in

[25] Nigeria. Tree and Forestry Science and Biotechnology 5(Special

[26] Ugese, F. D., Ojo A. A. and Adedzwa, D. K. 2007. Effect of sowing depth and seed size on emergence and seedling growth of seeds of shea butter tree (Vitellaria paradoxa). Nigerian Journal of Botany 20:93-102

[27] Zainudin, S. R., Awang, K. and Hanif, A. H. M. 2003. Effects of combined nutrient and water stress on the growth of Hopea odorata Roxb. and Mimusops elengi Linn. seedlings. Journal of Arboriculture 29: 79-83 